\title{
Application Research of VR Technology in College Sports Popularization and Teaching
}

\author{
Yaoliang Zhang \\ Zhuhai College of Jilin University \\ cpcimeici2018@163.com
}

Keywords: VR; College sports; Popularization; Teaching

\begin{abstract}
This paper aimed to explore the application method of VR technology in college sports popularization and teaching. In the research, this paper used the method of documentary analysis and comprehensive induction to explore the feasibility and specific method of VR technology in college sports popularization and teaching. The result showed that VR technology has both certain advantages and certain shortcomings in colleges sports popularization and teaching. Obviously, we can draw the conclusion that the integration of VR devices and college sports teaching can not only make teaching means more diverse to enrich the learning process and improve the teaching effectiveness, but also greatly motivate students' learning motive and interest to enhance their perception and enlighten their innovative association and creative thought to a greater extent. At present, VR technology has not been available in college teaching, and the certain talent pools and financial support have not been provided for the hardware and content development \& application. So we hope that the relevant departments and enterprises can tackle the technical issues, establish VR teaching and learning pilot and gradually innovate and improve the teaching model in the future to provide a new and futuristic teaching classroom for the teachers and students.

With the advent of the internet era, the integration of PE teaching and information technology has become more and more deep. Due to the introduction of MOOC and the interaction of flipped classroom, the momentous changes of PE teaching way and method have been caused. In modern college PE teaching, due to the shortage of space, facilities and resource for the training and experience of sports techniques, the amount and quality of training can not be guaranteed, and that may cause the relatively bad learning effect of motor skill and the low learning interest of students for $P E$ class $^{[1]}$. At the same time, for the technical movements that requires the specific movements of higher quality, the traditional teaching way both neither can make the initiators better understand the project, also is disadvantageous for the learners' fine perception and understanding. Now, the perfecting VR technology provides a good direction and thinking for the training of motor skill in $\mathrm{PE}$ teaching. The introduction of VR technology in PE teaching process can not only make the students better understand the characteristics of motor skill, but also make the advantages of information technology to be fully reflected in teaching by pertinently designing and displaying in accordance with each learner's interest ${ }^{[2]}$.
\end{abstract}

\section{The Feasibility Analysis for Application of VR Technology in College PE Teaching}

Stimulation of Sports Scenes to Breakout of the Restrictions of Time and Space. In college PE teaching, due to the certain teaching conditions restriction caused by different construction status of venues, VR technology has become very necessary. With VR technology, the three-dimension images of sports scenes can be stimulated and then displayed on the VR devices with help of a computer. In this way, the students can carry on a study through the sports scenes stimulated by VR devices without the restriction of space and time. At the same time, the shortage of teaching conditions is covered $^{[3]}$. For example, when the technical movements teaching of skiing is carried out, it is impossible that forty or fifty students go to a snow mount or skiing park to learn the technical movements. But through VR technology, the snow scenes simulation and the movements teaching of skiing can be realized. Through the glasses based on VR technology, the students can see the snow mount, skiing park, the simulated teacher with ski equipment, countless 
demonstrations of movements, decomposing teaching and timing analysis of action imitation process. The advantages of VR technology such as simplicity, convenience, authenticity and maneuverability greatly break through the constraints of time and space.

\section{Innovative Teaching Model to Improve the Students' Learning Interest and Teaching Effectiveness.}

The introduction of VR devices in college PE teaching classroom changes the traditional teaching model of listening-teaching due to its advantages such as immersion, interaction and imagination. In this teaching mode based on VR technology, the main role of students is fully played, and the students' initiative and enthusiasm to study are greatly improved. VR devices can help the students learn the teaching contents which can not be realized in the real teaching life by enriching the learning contents and forms. The more intuitive and vivid teaching activities with much physical stimuli provided by the virtual environment can improve students' association and innovative thinking ${ }^{[4]}$. For example, when teaching of the relatively abstract knowledge points such as the process of muscle fibers contraction and the bio-electric phenomenon of skeletal muscle cells in sports physiology are carried out, VR devices can be introduced for the dynamic simulation scenes teaching. With help of VR devices, the students can observe many simulative images of phenomenons such as the contraction of muscle fibers, myofilament sliding, excitation-contraction coupling of muscle fibers, action potential conduction simulation of skeletal muscle cells and excitation conduction between cells. From the first perspective of VR devices, the students can not only understand these phenomenons more intuitively and vividly, but also realize the system interaction and imagination simulation to greatly improve their learning interest and teaching effectiveness.

Digital Learning to Track Learning Data and Effectively Monitor Learning Activities.

Based on VR application design and teaching contents development, combined with VR devices and the auxiliary hardware, the digital learning is realized, i.e., digital simulative sports scenes ${ }^{[5]}$. Based on the maneuverability of scenes, the teaching forms and perspectives can be independently transformed in accordance with students' needs, and it can help to record the students' learning process, track the learning data, monitor the students' learning activities and effectively feed back the learning effectiveness according to the students' learning process and activities data. Therefore, the corresponding application designs and teaching contents development are very necessary for enriching and perfecting of more functions of system. Only in this way, when the students are immersed in the teaching scenes and system interaction, the system can scientifically monitor their learning activities and process and track their learning data to perfect the new teaching mode and effectively improve the teaching effectiveness.

\section{Strong Functional Development for the Broad Application Prospects in College PE Teaching.}

Based on VR application designs and contents development, combined with the follow-up system upgrade, more teaching functions still need to be developed, and the VR technology has a wild application prospects in college PE teaching. Now, the introduction of VR technology and devices in college PE teaching is still relatively few, and the VR application designs and contents development related to the college PE teaching are also relatively few. Therefore, the relevant technical departments can increase the investment on research and development of VR technology in college PE teaching to enrich its contents and perfect its functions. Some colleges can establish the VR physical education pilots to further perfect the function and content of its VR teaching system according to the students' usage conditions and teaching effectiveness. The specific functions and contents perfected includes the $3 \mathrm{D}$ virtual design picture, the picture with a wide range, the reduction of vertiginous sensation, the adding of interactive function, the enriching of digital learning monitoring and the data feedback. When VR technology of software and hardware are improved and perfected in PE teaching, and well introduced to the college PE teaching, VR technology will be popularized in the college PE teaching on a large scale with a more wild application prospects ${ }^{[6]}$. 


\section{Application of VR Technology in College PE Teaching}

\section{Application Situation of VR Technology in School Education at Home.}

With the innovation of educational ideas and the rapid development of computer technology, modern technology has infiltrated all aspects in the sports with its strong affinity, particularly the aspect of PE teaching training ${ }^{[7]}$. Beijing Weiku Science and Technology Ltd started very early in the field of VR technology. It independently researched and developed the "IES" immersive curriculum system by firstly introducing VR technology to school education teaching at home. In April in 2016, ZOL No. 2 Primary School of Beijing and Beijing Weiku Science and Technology Ltd launched the IES Immersive Teaching System. In 2015, New Oriental and Letv achieved the initial intent of cooperation that the two sides would carry out the virtual teaching in a English classroom. Anne Ltd also launched a project based on virtual reality technology that the technology would be used to develop the educational products for children. In 2017, Baidu established VR classroom in the school in poor mountain area. Xiamen Chuangyi Software Company developed the biggest 3D online interactive education cloud platform based on VR technology. Recently, NetDragon company has also announced that it is carrying out the implementation of VR technology in education at three levels of hardware, technology and resources. From the above cases, VR technology has come into people's life. In addition to the field of gaming, it will be widely applied in the fields of education and medicine. In 2016, the seminar on the application of VR technology and practical teaching information technology based on VR technology was held in Guangdong University of Technology. It means that VR technology will have a more broad cooperation space in the field of education ${ }^{[8]}$.

\section{Advantages of PE Teaching Based on VR Technology Compared to the Traditional PE} Teaching.

The application of VR technology can help teachers to carry out their teaching by providing the students with more fine guidance. Through VR technology, the teachers can capture and replay the students' movements at any time to check the normalization and accuracy of the students' movements. This can effectively reduce the stress of shortage of school teachers and fill the gap of teachers' level. Based on combination of VR technology and the internet and big data, the students' physical quality data, practice time and movement type can be recorded in the process of PE teaching, and the results can be regularly fed back to the students and teachers with help of a computer for the teachers' successful control of the students' training. From the students' perspective, the full-scale teaching environment simulation based on VR technology can make the students to be interested in the sports scenes, improve the enthusiasm of studying and be conductive to the students' mastering and understanding of sport skills. In addition, for the sports with various constraints such as space, facilities and safety, the required scenes also can be simulated through VR technology to break the constraints of time and space and realize the teaching target ${ }^{[9]}$.

\section{Inspiration of VR Technology on PE Teaching in Our Country}

\section{VR Technology Changes the Traditional Way of Teaching.}

As the information era has become more mature, the development of internet has greatly influenced many aspects of the society. The application of VR technology in PE teaching has a significant impact on the teaching target, teaching topic, teaching way, teaching content, teaching environment and performance evaluation. It certainly will promote the great reform of college PE teaching. The VR technology will completely change the traditional classroom teaching model of active teacher-passive student, and make significant changes in teaching content, teaching way and teaching environment.

VR Technology Provides A Good Opportunity for the Reform and Development of PE Teaching.

The development of VR technology and internet will bring the sports business and even the entire education a considerable progress. On the one hand, the application of VR technology in PE teaching will bring the huge impact on the traditional physical educational ideas and patterns in our 
country and affect the educational direction in the future with a strong binding effect. On the other hand, as a sprouting seed, the application of VR technology in college and university will be reasonable and mature more and more with the deepening of reform and accumulation of experience. It can be predicted that, in the future, the college PE teaching will be more modern and diverse because of VR technology $\left.{ }^{[10}\right]$.

\section{Rational Thoughts on the Implementation of College PE Curriculum Based on VR Technology in Our Country}

In the future, VR technology will change our lifestyles. But for now, its maturity and application still has a long way to go.

The Limitations of VR Technology in Cost and Technology.

Although VR technology has been proposed for a long time, its development has been relatively slow. VR technology is a kind of electronic technology product with higher R\&D cost and short renewal cycle. Therefore, it often occurs that the previous generation of products are obsoleted before starting making profits.

The Immature Hardware \& Software Development of VR Technology.

Some key problems of VR technology such as the motion sickness after wearing for a long time, the tactile equipment and the bad restoring capacity of reality remain unsolved. These problems limit the diversified development of VR technology and become the barrier of its application in the field of education teaching.

The Barrier of Communication \& Cooperation Between Students and Generation of Responsiveness Ability for Students.

learning itself is a process of cooperation which requires the mutual exchange and communication. If all the physical education teaching activities are carried out under the network environment, the preset, non-maneuverable and random system itself will make the learners produce the feeling of fatigue and the negative psychology as time passes. Thus, students can not adopt the changing sports in real life, and the training effect of adaptable and cooperative sports can not be realized.

\section{Conclusion}

The introduction of VR devices in college PE teaching can not only make teaching means more diverse to enrich the learning process and improve the teaching effectiveness, but also greatly motivate students' learning motive and interest to enhance their perception and enlighten their innovative association and creative thought to a greater extent. But now, the VR technology has not been available in college teaching, and the certain talent pools and financial support have not been provided for the hardware and content development \& application. Therefore, We hope that the relevant departments and enterprises can tackle the technical issues, establish the teaching and learning pilot based on VR technology and gradually innovate and improve the teaching model in the future to provide a new and futuristic teaching classroom for the teachers and students.

\section{References}

[1] Zhou Min. Research on Integration and Development Between VR Technology and Sports[J]. Science \& Technology of Stationery \& Sporting Goods, 2015(14):27-28.

[2] Yu Qianchun, Du ShiquaN. Application of Virtual Reality Technology in PE Teaching[J]. Journal of Anhui Sports Science, 2005, 26(4):115-117.

[3] Li Xueheng, Pei Jingjing. Applicaiton of VR Technology in PE Teaching[J]. Study of Computer Application in Education, 2016(6):107-108.

[4] Liu Yuan. Research and Application of VR Technology in the Field of Education[J]. Computer Knowledge and Technology, 2016.

[5] Zhang Jianwei, Tang Weidong. Exploration and Contemplation on the MOOC-Based College 
Sports Teaching Model[J]. China School Physical Education, 2016(3):72-78.

[6] Jin Xinwei, Wang Lijun. Development and Application of VR Technology in PE Teaching[J]. Journal of Mudanjiang Teacher's College (Natural Science), 2006(2):40-41.

[7] Fang Xiang, Wu Songwei, Zheng Hong. Challenges Faced By College Sports Teaching \& Countermeasures in the Information Era [J]. Sport World (Scholarly), 2016(11):95-96.

[8] Liu Heng, Feng Ting. Sports Teaching Mode Based on Virtual Reality Technology of Practice and Thinking[J]. Journal of Beijing Normal University (Natural Science), 2013(6):649-652.

[9] Fu Li, Zhao Jian. Research on the Application of Virtual Reality Technology in Education[J]. Digital Technology and Application, 2012(10):108-110.

[10] Hao Yan'e, Zeng Dehua. Virtual Reality (VR) Applications and Prospects of Technology in Digital Campus[J].Electronic Test, 2014(3):136-138. 